\title{
JUICIO A MIGUEL HIDALGO Y COSTILLA
}

RESUMEN: El traslado del manuscrito original de la Declaración del Padre Hidalgo ante sus jueces, es un documento histórico que, si bien ya había sido editado, resulta de gran importancia e interés para cualquier mexicano curioso del pasado de nuestro país. Hidalgo fue base y fundamento del desarrollo de un fenómeno histórico: el movimiento armado que derivará en la Independencia de México.

$$
\text { sose }
$$

ABSTRACT: The transfer of the original manuscript of Father Hidalgo's testimony is an historical document that, despite the fact that it has been published previously, has great significance and interest to every Mexican who is curious about his country's history. Hidalgo was the basis and foundation of the development of an historic phenomenon: the uprise which led to Mexico's Independence.

Palabras ClaVe: Hidalgo, juicio, insurgentes, Allende, Nueva España, Independencia. KEYWORDS: Hidalgo, trial, insurgents, Allende, New Spain, Independence.

RECEPCIÓN: 16 de febrero de 2010. APROBACIÓN: 15 de marzo de 2010. 
CITAM Derechos Reservados.

La reproducción total o parcial de este artículo se podrá hacer si el ITAM otorga la autorización previamente por escrito. 


\section{JUICIO A MIGUEL HIDALGO Y COSTILLA*}

\section{Introducción}

בne México Carso, institución privada al servicio de la investigación en nuestro país, se conserva un fondo que lleva por título "Lucas Alamán". Se trata del archivo particular del historiador decimonónico, quien se destacó enormemente por su participación política e histórica en el ala conservadora del gobierno, desde la Independencia hasta su muerte, a mediados del siglo XIX. El archivo no está completo, pues una sección se encuentra en la Latin American Collection, Nettie Lee Benson, de la Universidad de Austin, Texas.

En el fondo Alamán (CCLXXXVII), destaca un documento de gran importancia para conocer el pensamiento y las reflexiones de la primera lucha por la Independencia de la Nueva España de su metrópoli. ${ }^{1}$ Lleva por título Declaración del Padre Hidalgo ante sus jueces. Es un manuscrito original, llamado traslado, acerca del cuestionario a que fue sometido

* Paleografía: Manuel Ramos Medina, Centro de Estudios de Historia de México CARSO, Fondo Lucas Alamán, junio de 2009.

${ }^{1}$ Este cuestionario a Miguel Hidalgo ya ha sido publicado. No obstante, por la rareza bibliográfica, se justifica su reproducción. Ver Juan E. Hernández y Dávalos, Colección de documentos para la Historia de la Guerra de Independencia, 1887, México, El Sistema Postal. Una segunda edición de esta obra se publicó con el título La Santa Inquisición en los albores de la Independencia. Documentos. Los procesos militar e inquisitorial del Padre Hidalgo y de otros caudillos insurgentes, 1953, México, Ediciones Fuente Cultural, introducción y suplementos de Luis González Obregón, (edición de sólo 500 ejemplares). Finalmente, la edición de Antonio Pompa y Pompa, Procesos inquisitorial y militar seguidos a D. Miguel Hidalgo y Costilla, 1960, México, Instituto Nacional de Antropología e Historia. 
DOCUMENTO

el cura párroco del pueblo de Dolores, perteneciente al obispado de Valladolid (hoy Morelia, Estado de Michoacán), don Miguel Hidalgo y Costilla (1753-1811). El sacerdote disidente fue preso en Acatita de Baján, cerca de la villa de Monclova, en el actual Estado de Coahuila, el 7 de mayo de 1811, e inmediatamente enviado a la ciudad de Chihuahua, donde fue puesto en prisión y donde se le practicaron los interrogatorios.

El documento que se presenta ahora se paleografió del traslado ${ }^{2}$ que se resguarda en los acervos del Centro. Es una interesante fuente primaria relacionada con el proceso de Independencia, sin interpretación alguna, con la idea de que el lector forme sus propias conclusiones. Esto supone una lectura profunda, lo que seguramente va a cuestionar a la historia oficial en torno al padre de la Patria.

Miguel Hidalgo fue sometido a otro interrogatorio por parte de la jurisdicción eclesiástica, lo que causó mayor demora en su causa. La sentencia que se dictó como resultado de este segundo interrogatorio fue que el acusado, "reo de alta traición, mandante de alevosos homicidios: que se debe morir por ello, confíscársele sus bienes y que sus proclamas y papeles seductores, que deben ser dados al fuego público e ignominiosamente [...] que sea pasado por las armas en la misma prisión en la que está [...] y que después se manifeste al pueblo, para satisfacción de los escándalos que ha recibido por su causa".3

Don Miguel Hidalgo y Costilla fue una de las figuras más importantes, si no la principal, por ser el iniciador del movimiento armado, cuya personalidad vigorosa aglutinó los primeros impulsos de una serie de transformaciones en el orden social, político, cultural y económico de una nueva estructura de México; por eso hay que conocer a fondo al llamado "Padre de la Patria", como base y fundamento en el desarro1lo de un fenómeno histórico en que fue determinante, y en quien se conjugó la trágica aureola del iniciador, conformada en la misión de sacerdote y caudillo. ${ }^{4}$

${ }^{2}$ Un traslado es una copia manuscrita que se generó en el momento en que se llevó a cabo el cuestionario.

${ }^{3}$ Lucas Alamán, Historia de Méjico, desde los primeros movimientos que prepararon su independencia en el año de 1808 hasta la época reciente, 1850, Méjico,Imprenta de J.M. Lara, p. 192.

${ }^{4}$ Antonio Pompa y Pompa, op. cit., preámbulo, p. I. 
Hidalgo fue ejecutado el 29 de mayo de 1811. Por consideración a su carácter sacerdotal, la ejecución no se realizó en un paraje público, ni se le disparó por la espalda, sino al pecho. Su cabeza, con las de Allende, Aldama y Jiménez, fueron llevadas a Guanajuato y colocadas en jaulas de fierro en cada uno de los ángulos de la Alhóndiga de Granaditas. $^{5}$

\section{El cura de Dolores}

Nos encontramos con un personaje al que se le puede otorgar el título de ilustrado. Descendiente del administrador de la Hacienda de Corralejo, en la jurisdicción de Pénjamo, Intendencia de Guanajuato, obtuvo la experiencia necesaria de su padre para la administración de diversos negocios rurales de la época, mismos que puso en práctica una vez que le fue otorgado el curato de Dolores, después de que su hermano Joaquín, quien tuvo a su cargo el curato, había fallecido.

Su formación académica fue destacada. Realizó sus estudios en el Colegio de San Nicolás, en la pujante ciudad de Valladolid, donde se preparó en los campos de la filosofía y teología, logrando ordenarse como sacerdote en 1778, a sus veinticinco años de edad. Posteriormente, fue maestro del mismo colegio. La preparación intelectual de Miguel Hidalgo fue destacada. Llegó a ser Rector del Colegio de San Nicolás, a cargo de la Compañía de Jesús, donde había estudiado. Allí recibió el mote de El Zorro, por la gran personalidad e inteligencia con que era señalado desde el principio de su formación. Los colegios de los jesuitas han sido considerados como los semilleros de la conciencia criolla, es decir, transmisores de la identidad, de la pertenencia a estas tierras de las que se nutrieron y formaron, y Miguel Hidalgo es un ejemplo claro de esta formación.

La pasión por los libros lo llevó a formar una biblioteca con obras en diversos idiomas, pero especialmente en francés, lo que lo acercaba a los grandes sabios del virreinato de la Nueva España, que con tanta

${ }^{5}$ Lucas Alamán. op. cit., p. 203. 
DOCUMENTO

claridad observaban y reflexionaban en torno a los procesos políticos de Francia. En las noches especialmente, realizaba tertulias en las que pasaban largas horas con amigos y parroquianos, departiendo sobre literatura, ciencias, artes, industrias; se comentaban asuntos políticos fuera del reino de la Nueva España o de Europa. Recibía las Gacetas de México, llegadas en cada correo semanario y allí se enteraba de los resúmenes de la Gran Revolución, la declaración de guerra hecha a Francia por Carlos IV, primero, el tratado de paz, después, y otras muchas noticias. ${ }^{6}$

Durante su desarrollo como párroco, y dejando de lado su exclusivo trabajo pastoral, se dedicó a negocios propios que lo beneficiaban a él y a su parroquia. Hay que comprender la época. Los sacerdotes seculares (a diferencia de los regulares) podían acumular riqueza, al mismo tiempo que atender a la feligresía. En ocasiones, como fue el caso del Padre Hidalgo, los párrocos descargaban parte de su trabajo en algún presbítero con quien compartían la parroquia. Así, Hidalgo se apoyó en el padre Francisco Iglesias para atender las necesidades espirituales de su zona. Por ello, Hidalgo se pudo dedicar a las artes, agricultura y oficios diversos como el cultivo de la vid y de la morera, la cría de abejas, fábricas de loza, entre otras actividades.

Edmundo O'Gorman, al reflexionar en torno a Hidalgo, anotó que "aquel teólogo criollo, cura de almas pueblerinas, galante, jugador y dado a músicas y bailes; gran aficionado a la lectura y amante de las faenas del campo y de la artesanía, dio al traste con un gobierno de tres siglos de arraigo, porque si la vida no le alcanzó para saberlo, no hay duda que fue él quien hirió de muerte al virreinato". ${ }^{7}$ Y es realmente extraordinario el hecho de que la campaña militar del cura de Dolores, que se extendió únicamente por 120 días, hubiera dado resultados tan determinantes.

Su preocupación política fue constante. Muchos cuestionamientos lo persiguieron cuando Fernando VII abdicó al trono de España en favor Nación.

${ }^{6}$ Luis Castillo Ledón, Hidalgo. La vida del Héroe, 1948, México, Talleres Gráficos de la

${ }^{7}$ Edmundo O' Gorman, "Hidalgo en la Historia”, Discurso de ingreso a la Academia Mexicana de la Historia correspondiente de la Real de Madrid, en Imprevisibles historias. En torno a la obra y legado de Edmundo O'Gorman, 2009, México, Fondo de Cultura EconómicaUniversidad Nacional Autónoma de México, Facultad de Filosofía y Letras, pp. 379-99. 
de Napoleón Bonaparte. Esa coyuntura fue analizada detenidamente en "La Francia Chiquita", como se le llamaba a su casa, donde se llevaban a cabo las reuniones intelectuales. La amenaza de que Francia invadiera los reinos pertenecientes a la monarquía española fue una de las preocupaciones más fuertes de los novohispanos, porque la corona de España, bajo el dominio galo, se convertiría en una amenaza real contra la institución eclesiástica, como había sucedido después de la Revolución francesa.

Pero la situación interna del virreinato también trastocaba los intereses personales de Hidalgo. La cédula real de 1804, conocida como la de los Vales Reales, había forzado a la Iglesia a participar obligatoriamente en el préstamo de capital a la corona de España. ${ }^{8}$ El párroco de Dolores no fue la excepción. Esto, de alguna manera descalabró la economía del virreinato, al menos en algunas zonas, porque estudios más recientes muestran que no en todos los obispados se entregó el capital como se solicitaba. Hay que agregar a esto que el centro del virreinato sufrió, entre 1750 y 1813, malas cosechas y épocas de hambre. Los precios del maíz llegaron a aumentar hasta en un 300 por ciento mientras que los salarios se estancaron.

El movimiento de Hidalgo marca sin lugar a dudas el inicio del proceso histórico del movimiento de Independencia. Sin embargo, habría que aclarar ciertos puntos. No todos los habitantes de la Nueva España estuvieron de acuerdo con esta revolución. Es más, ni los indios ni las castas organizaron la defensa de sus intereses. Llama la atención, sin embargo, cómo se supo casi en todo el territorio el levantamiento del cura de Dolores, incluso en las provincias del norte, dirigidas por militares españoles. Pero el movimiento fue sofocado en menos de un año. Y aún cuando Morelos volvió a intentar una separación por las armas, lo que le costó la muerte y la de muchos de sus seguidores, a partir de 1815, exceptuando el movimiento del español Xavier Mina (1789-1817), quien luchó

${ }^{8}$ Gisela Von Wobeser, El crédito eclesiásticos en la Nueva España. Siglo XVIII, 1994, México, Universidad Nacional Autónoma de México, Instituto de Investigaciones Históricas; “Dominación colonial. La consolidación de vales reales en Nueva España. 1804.1812", Cuadernos de Historia Novohispana, Núm. 68, 2003, Universidad Nacional Autónoma de México, Instituto de Investigaciones Históricas. 
DOCUMENTO

contra los franceses, no volvió a darse una revuelta similar, aunque sí movimientos constantes.

Finalmente, la separación del Reino de la Nueva España de su metrópoli se operó en 1821 por Agustín de Iturbide, quien supo conciliar intereses y firmar el Plan de Iguala y los Tratados de Córdoba sin derramamiento de sangre. 


\section{Declaración del Padre Hidalgo ante sus Jueces}

Inmediatamente en dicho día siete de mayo de mil ochocientos once, el señor Juez Comisionado don Angel Abella en prosecución de las diligencias de que está encargado por el señor Comandante General se trasladó al hospital de esta villa en donde se hallan presos los reos don Miguel Hidalgo y consortes y constituidos en la prisión del expresado don Miguel Hidalgo teniéndolo en su presencia le recibió juramento que hizo in vervo sacerdotis tacto pectore et corona bajo el cual prometió decir verdad en lo que supiere y le fuere preguntado; y siéndolo por su nombre y apellido, edad, religión, estado, empleo, calidad y vecindad. Dijo: llamarse don Miguel Hidalgo y Costilla; cincuenta y ocho años de edad; estado presbítero, cura párroco del pueblo de los Dolores, obispado de Valladolid; español y su vecindad la de su curato.

1.- Preguntado: Si sabe la causa de su prisión; por quién fue aprendido; en dónde y qué otros sujetos fueron aprehendidos con él, sus nombres y carácter entre los Insurgentes y cuál es su paradero actual, particularmente el de los llamados don Ignacio Allende, don José Mariano Jiménez y don Juan Aldama: dijo que aunque no se la ha dicho la causa de su prisión, supone sea por haber tratado de poner en independencia este Reino. Que fue aprehendido por don J. Flores y un cuerpo de tropas que tenía a su disposición en el Puerto de Baján en la Provincia de Coahuila, cuyo cuerpo de tropas sería como de doscientos hombres: don Ignacio Allende nombrado Generalísimo; José Mariano Jiménez, Capitán General; don Juan de Aldama, Teniente General; don Mariano Abasolo, Mariscal; don Francisco Lanzagorta, Mariscal; don Manuel Santa María, Gobernador de Monterrey que era y ahora Mariscal; Don N. Carrasco, no se acuerda si Brigadier o Mariscal. Don José Santos Villa, coronel que fue de la insurrección de un regimiento; don Mariano Hidalgo, Tesorero General del Ejército; don Pedro de Aranda, mariscal; don J. León, no sabe su graduación; don N. Valencia que se agregó al ejército en Zacatecas ignorando con que graduación, como otros sujetos y todo su ejército a excepción de los que pueden haberse huido fueron aprehendidos con el que declara y los nombrados conducidos a esta villa desde la Monclova en unión del mismo quien actualmente ignora 
DOCUMENTO

su paradero; que el que declara ha tenido en la insurrección el carácter de Capitán General que se confirió en Celaya por el ejército que lo seguía desde el Pueblo de los Dolores, San Miguel el Grande y otros el cual conservó hasta Acámabaro que se le confirió por la oficialidad de dicho ejército el de Generalísimo y todo el mando político supremo, uno y otros con el tratamiento de Excelencia el cual se le convirtió después en el Alteza que unos se la daban simple, y otros con el aditamento de Serenísima pues así este tratamiento como el de Excelencia se lo dieron arbitrariamente sin orden ni acuerdo formal precedentes; que con este carácter siguió hasta que pedida la acción de Puente de Calderón en Guadalajara y retirándose sobre Zacatecas fue alcanzado en la Hacienda del Pabellón que está entre dicha ciudad y la villa de Aguascalientes por don Ignacio Allende, nombrado Capitán General desde que el que declara fue investido con el título de Generalísimo en Acámbaro, y en dicha Hacienda fue amenazado por el mismo Allende y algunos otros de su facción entre ellos el nombrado Teniente General Arias, Casas, Arroyo, únicos de quienes hace especial memoria, de que se le quitaría la vida si no renunciaba el mando en Allende, lo que hubo de hacer y lo hizo verbalmente y sin ninguna otra formalidad, desde cuya fecha siguió incorporado al Ejército, sin ningún carácter, intervención y manejo, observado siempre por la facción contraria y aún ha llegado a entender que se tenía dada orden de que se le matase si se separaba del Ejército lo mismo que contra Abasolo y el nombrado General Yriarte.

2.- A dónde y con qué objeto el mismo que declara y el ejército que dice marchaban por aquel rumbo de Baján y de Monclova, dijo: que el que declara marchaba con el ejército en los términos que deja expresados y más bien como prisionero que por propia voluntad y así ignora positivamente el objeto de esta marcha aunque presume que llevarían el de hacer de armas en los Estados Unidos; pero más el particular de Allende y Jiménez de aliarse con los caudales que llevaban y dejar frustrado a los que los seguían pues desde Zacatecas advirtió en Allende que procuraba deshacerse de la gente antes que de engrosarla y se lo advirtió mucho mejor luego que se juntó con Jiménez en el Saltillo, teniendo en prueba de esta presunción que el declarante les dijo allí que la gente se iba desertando y los dos le contestaron que no lo hacía. 
3.- Preguntado: Que por lo que tiene declarado se viene en conocimientos de que sabe y tiene noticia de la llamada insurrección que a mediados del mes de septiembre próximo pasado se suscitó en el Pueblo de Dolores y otros del distrito del virreinato de la Nueva España, diga quién o quiénes fueron los primeros y principales motores de ella; con quién y con qué medios contaron antes y después de promovida así de dentro como de fuera del Reino, quiénes los han fomentado con dinero, consejos, arbitrios, esperanzas o de cualquiera otras maneras; las concesiones y relaciones por escrito, de palabra o por interpuestas personas que hayan tenido con tales sujetos de dentro y fuera del Reino, y en dónde paran las constancias que acreditan todo lo referido.

Dijo: Que en efecto sabe y tiene noticia de lo que la pregunta inquiere y que la expresada insurrección tuvo principio en el expresado pueblo, el día diez y seis de septiembre próximo pasado, como a las cinco de la mañana; que los principales motores de ella fueron el que declara y don Ignacio Allende, en el modo y forma que va a expresar: que es cierto que el declarante había tenido con anticipación varias conversaciones con don Ignacio Allende acerca de la independencia, sin otro objeto por su parte que el de puro discurso, sin embargo de que estaba persuadido de que la independencia sería útil al Reino, nunca pensó entrar en proyecto alguno, a diferencia de don Ignacio Allende que siempre estaba propenso a hacerlo y el declarante tampoco lo disuadía, pues lo más que llegó a decirle en alguna ocasión fue que los autores de semejantes empresas no gozaban el fruto de ellas; que así se fue pasando el tiempo hasta principios del mes de septiembre referido que Allende hizo un viaje a la ciudad de Querétaro desde donde envió a llamar al declarante que pasase allá por medio de una carta en que le decía que importaba mucho y con estrechos encargos al mensajero de que le imitase al efecto; que habiendo accedido a sus instancias y estando en Querétaro, le presentó Allende dos o tres sujetos de poco carácter y que el declarante no conoce, y solo sabe que uno se llamaba don Epigmenio, los cuales se prestaban a sus ideas y decían tener a su devoción más de doscientos de la plebe; visto lo cual le pareció al declarante que aquello no tenía forma y se lo hizo presente a Allende, retirándose a su curato, aunque el Allende le significó que también por las haciendas de campo de aquellas inmediaciones, contaba con más gente; que Allende se quedó allí y a poco 
DOCUMENTO

tiempo volvió a escribir al declarante que efectivamente aquello no valía nada, a que le contestó que no contase con él para cosa alguna; que seguidamente volvió a San Miguel el Grande a escribir al declarante, que ya las cosas habían variado; y que se le había presentado mucha gente así en Querétaro y como en las haciendas después de la última que le había escrito, con lo cual ya se redujo el declarante a entrar por el partido de la insurrección y en consecuencia empezó a dar algunos pasos hacia la ejecución, mandando hacer como unas veinte y cinco lanzas que se fabricaron en el mismo pueblo de Dolores y Hacienda de Santa Bárbara perteneciente a los Gutiérrez que eran sabedores de lo que se trataba, encargando a estos que hiciesen gente citándolos para el día que los llamase; tratando con el tambor mayor del batallón de Guanajuato llamando Garrido, el cual quedó en hablar a la tropa y no sabe lo que practicó en razón del caso: que en esto como tres o cuatro días antes del día diez y seis, tuvo el declarante noticia aunque vaga de que Allende estaba delatado por lo que lo llamó a Dolores para ver lo que él resolvía; pero nada resolvieron en la noche del catorce que llegó a su casa ni en todo el día quince que se mantuvo allí; hasta que a las dos de la mañana del 16, vino don Juan Aldama diciéndole que en Querétaro habían prendido a sus confidentes; en cuya vista en el mismo acto acordaron los tres dar el grito, llamando para ello del declarante como diez de sus dependientes y dando soltura a los presos de la cárcel obligando al carcelero con una pistola a franquear las puertas de ella y entonces les previno a unos y a otros que les habían de ayudar a prender a los europeos, lo que se verificó a las cinco de la mañana del mismo día, sin otra novedad que la de unos cintarazos que se dieron a don José Antonio Larrinua por que se iba huyendo; que puestos en la cárcel los europeos, cerradas las tiendas de unos, dejadas otras a cargo de los cajeros criollos o de sus familias y viniéndose a un partido los indios y rancheros que por ser domingo habían ocurrido a misa, trataron de encaminarse a San Miguel el Grande en prosecución de su proyecto. Que como el declarante solo trató con Allende este negocio en los términos que deja expresados y la prisión de los confidentes de Querétaro, lo precipitado no tuvo dentro ni fuera del Reino conexiones ni relaciones algunas por escrito ni de palabra, ni por interpuestas personas, antes ni después de la insurrección, ni sabe que antes ni después las hayan tenido Allende y los demás 
que sucesivamente se fueron agregando en calidad de principales cabe de dicha insurrección; ni sabe otra cosa que lo que se resulta de lo que lleva declarado en esta su posición respecto de sí y de Allende. En este estado y por ser ya las dos de la tarde mandó el señor juez Comisionado don Angel Abella, suspender esta declaración para continuarla en la tarde de este mismo día la cual leída que le fue al declarante dijo: ser la misma que lleva prestado, en que se afirmó y ratificó y firmó con dicho señor Comisionado y consigo el presente escribano de que doy fe. Angel Abella. Miguel Hidalgo. Ante mí. Francisco Salcido.

En la tarde del mismo día el juez comisionado continuando la declaración que quedó pendiente y teniendo presente al declarante bajo el juramento ya prestado lo verificó y en tal virtud.

4.- Preguntado: Cómo fue un sujeto de las luces y conocimientos que se le conceden generalmente y que se mostraba indiferente y sin empeño por la independencia se decidió a este partido por la carta última que dice haberle escrito Allende indicándolo en términos generales que las cosas habían variado mucho, sin detenerse a examinarla, ni saber los sujetos, relaciones, conexiones y medios con que se podía contar para llevar adelante la empresa, y cómo después de principiada no había de haber procurado por sí y por sus Agentes los arbitrios de sostenerla por medio de ganar sujetos, y de facilitarse tales relaciones y conexiones. Dijo que antes de dar el grito no pasó más que lo que tiene declarado, y que su inclinación a la independencia fue lo que le obligó a decidirse con tanta ligereza o llámese frenesí que la precipitación del suceso de Querétaro no les dio lugar a tomar las medidas que pudieran convenir a su intento y que después ya no los consideraron necesarios mediante la facilidad con que los pueblos los seguían y así no tuvieron más que enviar comisionados por todas partes, los cuales hacían prosélitos a millares por donde quiera que iban.

5.- Preguntado: Si sabe o tiene noticia que el tal motor o motores de ella han tomado por pretexto a sus intentos trataban de entregar el Reino los europeos a una potencia extranjera, y si para seducir a los incautos y plebe ignorante se les han dado a saco sus bienes en parte y 
DOCUMENTO

parte reservándola para sí mismos o para otros fines; diga para qué fines y en dónde vio o vieron las constancias de aquel supuesto trato o entrega.

Dijo: Que no se acuerda haberlo tomado por pretexto aunque sí haberlo oído decir y que lo dejó correr porque no dejaba de contribuir al logro de ellos; pero que no ha visto constancia auténtica de semejante trato. Que es cierto que a la plebe se le dieron a saco muchos bienes de europeos y otra parte se reservaba para mantener las tropas.

6.- Preguntado: Si sabe o tiene noticia como parece por lo que lleva declarado que él mismo o los mismos motores a fin de llevar adelante la insurrección han levantado ejércitos, atacado o hecho frente con ellos a los del Rey; acuñado monedas, fabricando cañones, armas y municiones; nombrado generales, oficiales y toda suerte de empleos militares apoderándose de los caudales del Rey y de los de las iglesias; de los de los europeos, y también de los de los criollos, ya porque no abrazaban su partido, ya porque les hacían al caso; depuesto, perseguido y muerto las autoridades establecidas y legítimas; sustituido otras a su albedrío, dado y quitado empleos en todos ramos; despachado por todas partes emisarios a seducir los pueblos y otros a solicitar auxilios de Potencia o Potencias extranjeras, diga cuanto sepa y tenga entendido en orden a lo que se le pregunta.

142 Dijo: Que el declarante los ha levantado, atacado y hecho frente con ellos a los del Rey; que ha fabricado moneda en Zacatecas y se debía haber practicado en Guanajuato si se hubiera concluido el ingenio proyectado; que también fabricó cañones, armas y municiones; y lo mismo nombró generales y otros oficiales cuya prerrogativa no era exclusiva del declarante, pues también el Capitán General y los demás Generales que se hallaban distantes del centro del Gobierno y el cuerpo de la oficialidad hacía y promovía los que se les antojaba; que también han tomado de las Cajas los caudales que se hallaron y varias cantidades de las Iglesias Catedrales, de Valladolid y Guadalajara y la de los europeos como tiene declarado, y de los criollos se tomaban caballos y lo que los hacía al caso con calidad de reingreso; que han depuesto las autoridades establecidas, si eran europeos o criollos que no seguían su partido; que han perseguido a muchos de ellos y muerto solo cuenta al Intendente de Guanajuato don Antonio Riaño; que por la misma regla han dado y quitado empleos 
de todas clases; que en cuanto a emisarios ya tiene declarado en la posición cuarta y en cuanto a los enviados a Potencias Extranjeras, el que declara en unión de Allende despacharon a un don N. Letona, natural de Guatemala a los Estados Unidos a solicitar su alianza y armas, con poderes amplios y expresos de ofrecerles el libre comercio, y no tiene presente qué otra cosa se les ofrecía, lo cual pasó por el mes de diciembre próximo pasado, e ignora si este encargado llegó a su destino, aunque ha oído decir que fue muerto en el camino; que también ha oído decir a Allende que él por sí solo había despachado al licenciado don Ignacio Aldama con igual objeto, sin contar con el que declara y es cuanto se puede decir sobre los particulares de que es interrogado.

7.- Preguntado: Si supo o tuvo noticia de un edicto del Santo Tribunal de la Fe, implorando al declarante a comparecer en el término de treinta días, como cabeza de la expresada insurrección y responder a los cargos de herejía que le resultaban por causa pendiente en dicho Tribunal, excomulgándoles y a todos sus secuaces en caso de no comparecer y si también supo o tuvo noticia de las excomuniones que contra él mismo y sus partidarios fulminaron los prelados de todas las iglesias de Nueva España, y en ver de obedecer tan respetables preceptos los ha despreciado y hecho que los Insurgentes por cuantos medios estuvieron en su mano, los despreciasen y particularmente imprimiendo y publicando los escritos al intento en la ciudad de Guadalajara.

Dijo: Que sí supo de tal edicto por una carta que desde Querétaro escribían a un soldado del Ejército en que se referían los artículos de que se le acusaba, pues no ha leído el Edicto, ni trató de hacerlo mediante que no pensaba comparecer, temeroso de ser castigado, no por los delitos de herejía de que se le acusaba, sino por el Partido en que estaba empeñando, así como también para sostenerse como este, se consideró en la necesidad de impugnarlo y si en la ejecución ha faltado en algo al decoro y respetos debidos al Santo Tribunal, todo fue efecto de las críticas circunstancias en que se hallaba, lo cual le ha causado entonces y después no pocas angustias en lo íntimo de su corazón y de que se haya arrepentido vivamente como lo declara aquí en obsequio de la verdad y de la religión santa que profesa. Que de las excomuniones de los Prelados, solo tuvo noticia de las de su Diocesano, en el camino de Guanajuato a 
DOCUMENTO

Valladolid, la que no le detuvo por el mismo empeño en que ya se hallaba y cuando llegó a dicha ciudad ya el Cabildo había levantado la expresada excomunión, ignorando el motivo de este alzamiento, aunque siempre consideró sería con el prudente de evitar mayores males espirituales.

8.- Preguntado: Si supo y tuvo noticia y la tuvieron los compañeros de los indultos publicados por el Excmo. Sr. Virrey de este Reino, y particularmente el publicado en principios de Enero próximo pasado a favor de toda la masa de insurgentes que depusiesen las armas, y se retiraran pacíficamente a sus casas quedando el que declara y el nombrado don Ignacio Allende a disposición del gobierno soberano nacional, y si en vez de acogerse a él, no solo no lo ha hecho, sino que lo ha ocultado a sus secuaces y dado al Exmo. Sr. Virrey una contestación conforme en todo a los principios adoptados para su partido.

Dijo: Que por lo que toca, no tuvo más noticia que del último a que se refiere la pregunta y esto por la casualidad de haber ido el que declara a casa del llamado General Jiménez, en ocasión que este estaba tratando con Allende sobre el mismo indulto, el cual había dirigido a Allende el Comisionado Blancas, quien lo había recibido por dirección del Sr. Rebollo de Querétaro, para que lo remitiese al que Declara y a Allende con cuyo motivo se lo manifestó este y acordaron, no acogerse a él por

144 la restricción con que venía respecto de ellos y este habrá sido el motivo por qué allende no lo hizo saber a mi ejército, sin culpa alguna del declarante, porque ya no tenía autoridad ni carácter; que el que declara ha puesto un borrador para la contestación que debía darse al Excmo. Sr. Virrey el cual o no pareció bien a Allende o habrá formado otro pues sabe que efectivamente contestó a su ejército; no sabe si por sí solo o en unión de Jiménez y otros pues a fin al que Declara no se le pidió su firma para ninguno.

9.- Preguntado: Si por ventura el Borrador de que habla es el que se manifiesta y se registra a fojas primera del cuaderno a que se refiere el oficio de comisión del Sr. Comandante General, que obra por cabeza de estas actuaciones y en caso de ser el mismo, que lo señale con su media firma al margen para la debida constancia.

Dijo: Que el borrador que se le manifiesta es el mismo que dictó para el expresada contestación y lo señala como se dice para la debida constancia. 
10.- Preguntado: Si el mismo que declara ha escrito o se han escrito de su orden aprobaciones o consentimiento publicado y circulado proclamas impresas o manuscritas y otros papeles sediciosos y particularmente una proclama manuscrita a fojas dos, y otra impresa a fojas 22 del referido cuaderno y el periódico titulado Despertador Americano que se publicaba en Guadalajara y quién o quiénes fueron los autores de tales escritos incendiarios si no lo fue el declarante y que señale las que se le manifestaban, si las reconociere por suyas o escritas de su orden, como el papel de la posición antecedente.

Dijo: Que sabe se han escrito y publicado y circulado muchos papeles de la clase que inquiere la pregunta cuyos autores ignora porque ellos de propio movimiento los escribía de los cuales ha visto algunos entre ellos uno que supo ser del Padre Saavedra, dominico del convento de Zacatecas que declara solo ha escrito el manifiesto en respuesta del Edicto del Santo Tribunal de la Fe, y otro cuyo objeto es probar que el americano debe gobernarse por americano así como el alemán por alemán. Y de su ejército la impresa que se la manifiesta y señala en la forma que la antecedente para la debida constancia que también se publicaba de su ejército en Guadalajara por el Dr. Maldonado El Despertador y que no es suya la manuscrita que se le manifiesta.

11.- Preguntado: Si él mismo antes o durante la insurrección, ha predicado en los púlpitos o ejercitado el confesionario, abusando de la santidad de ambos ministerios para adelantar y mantener su partido por la seducción de las conciencias o si sabe que así lo hayan practicado los malos sacerdotes que se declararon a su favor y lo ha tolerado; y finalmente si él mismo ha aconsejado, seducido, violentado o pretendido violentar a los buenos a que así lo practicasen o impedioles predicar y cualesquiera otras funciones de su ministerio contra el partido de la insurrección; y diga lo que sobre el particular le haya acontecido en Guadalajara, Guanajuato, Zacatecas y otros pueblos y cuanto tenga relación con lo que la pregunta inquiere.

Dijo: Que por si ni antes, ni en el curso de la insurrección ha predicado ni ejercitado el confesionario, con abuso de la santidad de sus ministerios; y por lo que hace al tiempo de la insurrección ni para bien ni para mal, ha ejercitado ni el uno ni el otro, ni tampoco ha celebrado 
DOCUMENTO

el santo sacrificio de la Misa, por considerarse inhábil para el ejercicio de toda función eclesiástica y en el modo que ha podido ha procurado respetar los sentimientos religiosos que abrigaban su interior; que no sabe si otros sacerdotes han abusado del confesionario para los fines de la pregunta pero sí que han predicado algunos como el Dr. Maldonado en Gualajara y el religioso fray Gregorio Conde en Guanajuato; lo que les ha tolerado, desentendiéndose de ello por su propia conveniencia y consecuencia del empeño en que estaba metido; que tampoco ha aconsejado, ni inducido a los buenos ni a los malos a predicar ni confesar con abuso de su ministerio, aunque por consecuencia de su compromiso ha reprendido al padre Corona en Guadalajara y ha llegado a arrestarle porque predicó contra la insurrección y porque no repicó cuando la toma de San Blas, no habiendo tomado providencia más rigurosa contra dicho padre, sin embargo de las fuertes alteraciones que sostuvo con el declarante, porque su misma firmeza le impuso al mismo tiempo que le complacía en su interior de suerte que el declarante nunca exigió de los predicadores autos positivos a favor de la insurrección y se contentaba con que no predicasen contra ella y nada ha exigido de los eclesiásticos con respecto al confesionario; que en Zacatecas pidió un padre al Señor Guardián de Guadalupe, porque pensando en dirigirse

146 a las provincias internas del Oriente, parecía conveniente llevar en el ejército un religioso de dicho convento, aunque no fuese sino como de perspectiva para aparentar con aquellos pueblos una tácita aprobación de su partido y habiéndolo negado el expresado padre R. P. Guardián con recado que le envió con el padre Escalera del mismo convento no trató de hacerle violencia y únicamente le hizo contestar por el padre Mensajero, que sentía su negativa y que debía saber que en su mano estaba llevar uno o más padres, los que quisiese; y en efecto salieron de aquella ciudad sin padre alguno Guadalupano; y que es de advertir que aunque como ya tiene declarado, desde la Hacienda del Pabellón no tenía autoridad ni mando alguno, todavía no se había hecho público su despojo y solo andaba en susurro entre las gentes, todavía la facción contraria lo hacía parecer principal cabeza y tenerlo por parapeto hasta la ocasión y por eso fue que indicando el declarante por propio interés a Allende lo conveniente que les sería llevar un padre Guadalupano aquel 
le dijo, o más bien le mandó que se lo pidiesen al R. P. Guardián. Que es cuanto puede decir.

12.-Preguntado: Como Generalísimo nombrado y jefe en todos ramos como tiene declarado, qué armas o escudos ha señalado a las banderas y estandartes de sus llamadas tropas; y si ha mudado los que tenían los regimientos que se hicieron a su partido; si en efecto ha asignado a unos y otros por armas la imagen de Nuestra Señora de Guadalupe y a Fernando VII, y qué fines se ha propuesto en hacerlo así, si fue por reducir mejor a los pueblos, especialmente a los indios, por el conocimiento que tenía de la devoción a esta santa imagen de estar hasta entonces imbuidos en los principios de una justa adhesión a su legítimo soberano.

Dijo: Que realmente no hubo orden ninguna, asignando armas algunas. Que no hubo más que habiendo salido el declarante el 16 de septiembre referido con dirección a San Miguel el Grande, al paso por Atotonilco tomó una imagen de Guadalupe en un lienzo que puso en manos de uno para que la llevase delante de la gente que le acompañaba, y de ahí vino que los regimientos pasados y los que fueron después formando tumultuariamente, igualmente que los pelotones de la plebe que se les reunía, fueron tomando la misma imagen de Guadalupe por Armas, a que al principio agregaban generalmente la del Señor don Fernando VII y algunos también la Aguila de México, pero hacia estos últimos tiempos, ha notado que se hacía menos uso de la imagen de Fernando VII que a los principios parcialmente en la gente que mandaba el llamado General Yriarte, cuyo motivo ignora, pues ni él ni Allende dieron orden ninguna sobre este punto, ni tampoco realmente se puede hacer alto sobre él pues al fin cuanto se hacía era arbitrario y que la ocurrencia que tuvo de tomar en Atotonilco la Imagen de Guadalupe, la aprovechó por parecerle a propósito para atraerse las gentes pero debe también o debería que la expresada imagen de Guadalupe que al principio todos tenían en los sombreros, al fin eran pocos los que la usaban, sin saber decir cuál fuere la causa.

13.- Preguntado: Si conoce qué fue a hacer un abuso sacrílego en tomar la Santísima Virgen con el designio que deja declarado y el de autorizar con su Santo Nombre, el atentado que lo dirigía y llevaba a San Miguel el Grande de poner en insurrección aquella villa, prender por lo 
DOCUMENTO

pronto a los europeos de ella y finalmente, los robos, muertes y escándalos que necesariamente debían seguirse de su empresa.

Dijo: Que por entonces no previó el abuso que podía hacerse y se hizo después del Santo Nombre de la Virgen porque ocupada su fantasía de los arbitrios y medios que tomaría para sorprender a San Miguel el Grande, no le quedaba lugar de pensar sobre las consecuencias futuras y por eso adoptó aquel medio.

14.- Preguntado: Si no obstante lo que tiene declarado en su tercera posición, si él mismo o Allende, o alguno otro de sus confidentes fue sugerido directa o indirectamente por Bonaparte o alguno de sus emisarios para promover esta insurrección pues a más de ser esta la opinión común, el empeño de dicho Bonaparte y anunciarse en sus Gacetas del mes de septiembre próximo pasado, una revolución muy próxima en la América, sobre principios idénticos a los que de hecho el declarante y consortes publicaron a sazón en los pueblos de Dolores, San Miguel el Grande y demás, hace muy probable el común sentir. Diga si ha conocido o tratado al General Francisco Dalvimar, qué conversaciones ha tenido con él a su tránsito por Dolores y si sabe o sospecha que haya seducido a alguno y cuanto sepa en razón de la pregunta.

Dijo: Que de sí mismo sabe y asegura que no ha sido sugerido por

148 Bonaparte, ni emisario suyo, sin que haya en el caso más francés que lo que tiene declarado en la citada posición. Que habló al General Dalvimar al paso por Dolores, desde el anochecer hasta como hora y media en unión de otros varios vecinos criollos y europeos vecinos honrados del pueblo, en cuyo tiempo se habló del Emperador Bonaparte, del General Moreau y noticias generales de esta clase con que el declarante se despidió y no volvió a verlo más ni tener noticia de su paradero que tampoco sabe que Allende haya sido sugerido, ni otro alguno por Dalmivar o emisarios cualesquiera de Bonaparte; bajo cuyo supuestos ignora el fundamento de la Gaceta Francesa para el anuncio referido, aunque confiesa que este da bastante probabilidad al común sentir; a no ser que hubiese algunos otros confabulados con Bonaparte y sus emisarios y es cuanto tiene que decir acerca de la pregunta.

15.- Preguntado: Si es cierto como ha sido voz común que la insurrección verificada el día 16 de septiembre, estaba resuelta para el 29 día de 
San Miguel en la Villa de San Miguel el Grande y si en esto el declarante llevaba el objeto de dar cierto aire de prodigio a dicha insurrección, reuniendo las circunstancias de su propio nombre el del santo del día y el del lugar de su plantificación a la manera que se valió de la Imagen de la Virgen Santísima de Guadalupe para atraerse los pueblos.

Dijo: Que no es cierto que hayan tenido semejantes consideraciones con respecto a ninguna de dichas circunstancias. Que sí se trató de que se verificase el día veinte y seis en la ciudad de Querétaro y en San Miguel el Grande, pero habiendo parecido corto el tiempo para prevenir de algunas armas, se defirió para el día 2 de octubre, lo que no tuvo efecto por la sorpresa de los confidentes de Querétaro, como tiene declarado en la posición tercera.

16.- Preguntado: Si sabe y tiene noticia de los asesinatos que son notorios de Guanajuato, Guadalajara, Valladolid, Charcas, Real de Catorce, Matehuala, y otros pueblos cometidos en las personas de muchos europeos y criollos sin forma alguna de proceso, ni aún concederle el último consuelo de confesarse. Si él mismo o sus secuaces de orden suya verbal o por escrito o con su consentimiento y conveniencia los han o se han ejecutado y quién o quiénes fueron los ejecutores de estos horrorosos crímenes.

Dijo: Que sabe y tiene noticia de los referidos asesinatos, que no ha tenido parte en los de Guanajuato, porque al tiempo de la reconquista de esta ciudad por el Señor Calleja, se hallaba el declarante en Guadalajara; pero que sí la tuvo en los de de Valladolid que fueron ejecutados de su orden y serían como sesenta los que perecieron; que por la misma razón la tuvo en los de Guadalajara, que ascendían como a trescientos cincuenta entre ellos un lego carmelita y un dieguino, si mal no se acuerda; que no sabe si era lego o sacerdote. Y que no tuvo parte en los que se ejecutaron después, ni sabe de orden de quien se ejecutaron aunque supone había sido de la de Allende, como quien tenía ya todo el mando; que es cierto que a ninguno de los que se mataron de su orden se les formó proceso si había sobre qué porque bien conocía que estaban inocentes; pero sí se les dio confesores cuyos nombres ignora y sabrán los que asistían a estas ejecuciones, las cuales se ejercitaban en el campo a horas desusadas y lugares solitarios para no poner a la vista de los pueblos un espectáculo tan horroroso y capaz de conmoverlos; pues únicamen- 
DOCUMENTO

te deseaban estas escenas los indios y la ínfima canalla; que en Valladolid conducía las víctimas al lugar del suplicio un Manuel Muñiz, natural de Tacámbaro, con grado de Capitán y los ejecutores indios; que él mismo graduado ya de Coronel condujo porción de los de Guadalajara como también un Vargas, Coronel, natural de Cotija. Otros un Cajiga, Capitán, de Pénjamo o de San Francisco Angamacutiro, y los últimos Agustín Marroquín, Capitán y un Coronel Alatorre de hacia Aguascalientes y de otros también fueron ejecutados los indios de las inmediaciones de la misma ciudad; que los asesinatos de Guanajuato, tiene entendido, fueron dispuestos y ejecutados por aquella plebe. Y que a más de la razón que deja indicada para creer que Allende mandó los de Matehuala y demás, en haber oído que un tal Soya que le servía, los condujo al suplicio o los mató por su mano, aunque ignora lo cierto de estos extremos.

17.- Preguntado: Que motivo tuvo para un proceder tan inhumano con unos hombres que confiesa inocentes y a quienes había despojado de su libertad y de sus bienes arrancándolos del seno de sus familias y reducídolos a un estado de no poderlos ser dañosos.

Dijo: Que no tuvo más motivo que el de una condescendencia criminal con los deseos del ejército, compuesto de los indios y de la canalla, como tiene dicho en la pregunta antecedente.

18.- Preguntado: Cómo pues este ejército compuesto de indios y de canalla gente que no guarda consideración con los de mayor esfera cuando se reconoce superior, se contentaba con que tales asesinatos se ejecutasen a horas desusadas y parajes solitarios, contra lo que se ha visto siempre por experiencia en todos los desórdenes públicos que es complacerse no solo en ver, sino en ejecutar por sus propias manos semejantes atrocidades.

Dijo: Que reconoce bien el fundamento de la réplica pero que realmente la cosa pasó como lleva declarado.

19.- Preguntado: Si además de haberlos asesinado en la forma dicha, ha publicado o consentido publicar contra ellos, y contra todos los que prestasen cualquier género de favor y ayuda o auxilio aunque fuese nacido de sola compasión, bandos inhumanos y opuestos a toda ley Divina y humana y reconozca si es autor del que se le manifiesta y se halla a continuación de una Proclama que tiene declarado ser suya y empieza a fojas 19 vuelta del cuaderno citado en otras preguntas anteriores. 
Dijo: Que ningún Bando de la naturaleza que se le pregunta ha publicado, ni consentido publicar y niega ser suyo el que se le manifiesta, ni sabe de quién es, ni hasta ahora que se le manifiesta lo había visto.

20.- Preguntado: Si entre los asesinados había algunos indultados, una o más veces por él mismo y por sus subalternos y por qué no ha respetado y hecho respetar estos indultos; o tales indultos fueron un refinamiento de la más inicua política.

Dijo: Que algunos había indultado o por mejor decir que lo habían sido y se les habían recogido los indultos, sobre denuncias al parecer fundados, de abuso, aunque nunca se hizo proceso en razón de ellos, y como quiera que el que declara no trata de justificarse en razón de esto pues ya tiene confesado que procedió criminalmente en la muerte que se les dio por lo demás en los indultos y que concedió el declarante no ha llevado ningún fin torcido de política.

21.- Preguntado: Con qué derecho se creyó él mismo y sus secuaces para la usurpación de los bienes de los europeos asesinados y no asesinados, reduciendo a la miseria a sus mujeres, hijos y dependientes naturales del País viniendo a resultar el principal daño y perjuicio inmediato contra los criollos; y por qué él mismo y sus secuaces, si pensaban obrar en consecuencia no se despojaron también de los bienes que muchos de ellos deben de haber heredado de sus padres y antepasados, no adquiridos seguramente de con mejor derecho.

Dijo: Que bien conoce que tal usurpación era no solo injusta sino perjudicial y contraria inmediatamente a los intereses de los mismos criollos; pero la necesidad que tenían de gente para su empresa y la de interesar en ella a la plebe, no les permitía escrupulizar sobre los medios de llevarla adelante y también reconoce la inconsecuencia de su obrar. Pero no es lo mismo cortar de lo ajeno que de lo propio y por eso no hubo ninguno de los comprendidos en la insurrección que pensase en hacer el sacrificio de lo que muchos han heredado.

22.-Preguntado: Qué ha hecho él mismo o han hecho sus secuaces de tantos caudales, así metálico como en efectos de todas clases, tanto del Rey como de los particulares y los que tomado de las iglesias y si además de los que se les aprendieron en Baján, sabe si han quedado otros en el interior del Reino, escondidos o depositados en poder de confidentes, en dónde y en poder de quiénes. 
DOCUMENTO

Dijo: Que aunque es cierto que la masa de la insurrección se ha apoderado y dilapidado muchos caudales de todas clases, no es grande la cantidad que ha entrado en el fondo de ella, pues por lo que toca al declarante apenas había entrado en su poder un millón del que se quedaron cerca de trescientos mil pesos en Aculco; doscientos mil que entregó a Allende en Zacatecas y lo demás lo gastó con las tropas pues no siempre hubo gran número de gente a quien pagar ya por las dispersiones que han sufrido ya porque cuando pudieron hacer pie en algún punto se despachaba toda gente de sus inmediaciones a sus casas hasta que urgía llamarlos ya porque muchas veces les pagan en efectos y por esto bastó para las pagas el corto resto que queda de la expresada cantidad, ignorando lo que habrían cogido y gastado las cabezas que se hallaban distantes mandando cuerpos de esta gente porque al declarante nunca le daban cuentas a consecuencia del desorden que reinaba en todos; que tampoco sabe si algunos individuos habían dejado cantidades escondidas o depositadas pues es natural que si en efecto las dejaron tendrán buen cuidado de no revelarlo a nadie.

23.- Preguntado: Si entre los caudales que han tomado de las iglesias había alhajas o vasos sagrados de ellas.

Dijo: Que ninguna alhaja ni vaso sagrado de las iglesias ha tomado

152 él mismo, ni sabe que lo haya tomado alguno otro de las cabezas de la insurrección.

24.- Preguntado: Con qué derecho y con qué autoridad se tomaba el que declara, los caudales de las iglesias y qué términos lo hacía, así en cuanto a el modo de tomarlos, como al de satisfacerlos.

Dijo: Que no se consideraba con más derecho ni autoridad que él mismo con que tomaban los demás de los particulares, y es el que tiene declarado a la pregunta veinte y uno y que en cuanto al modo, no se hacía más que pasar a los cabildos un oficio y no se acuerda si en Valladolid fue recado verbal, para que manifestasen los caudales que tenían y que de los bienes de la Nación se les satisfarían y así se tomaron sin más formalidad de la iglesia de Valladolid una cantidad que no se acuerda pero la tendrá presente don Juan de Aldama, que fue el comisionado y de la de Guadalajara como cincuenta y seis mil pesos de que fue comisionado un Avendaño de Zamora, que fue nombrado oidor de aquella Audiencia 
por el que declara, y del Juzgado de Testamentos se tomaron también por el mismo estilo como setenta mil pesos.

25.- Preguntado: Si creía de buena fe que estas deudas y otras que sería necesario contraer podrían satisfacerse jamás, cuando no podía dejar de conocer que el Reino iba a quedar desolado aun cuando diera el caso de realizarse su empresa en todas sus partes.

Dijo: Que entonces lo creía de buena fe aunque nunca se detuvo a calcular el estado de vigor y fuerza en que quedaría el Reino, en ningún caso, bien que siempre lo hubieran tomado por las razones que tiene indicado en otras preguntas.

26.- Preguntado: Cómo es creíble a pesar de lo que tiene declarado de la ligereza a un frenesí con que se entregó al partido de la insurrección por las simples sugestiones de Allende que no haya procurado indagar y saber de este los apoyos que contaba para el logro de su empresa en México, Guadalajara y otros Pueblos principales del Reino, ni que el mismo Allende le haya manifestado sus relaciones y confidencias aunque no fuere sino para moverle viéndolo remiso, y aunque positivamente se le había negado de resultas del poco concepto que le habían merecido los confidentes de Querétaro.

Dijo: Que no hay más que lo que tiene dicho en la posición tercera y cuarta; fue una ligereza inconcebible y un frenesí pues aunque alguna vez y mucho antes de tomar tal resolución le habló Allende de que el Marques de Rayas, y un Fagoaga, pensaban en cierto modo análogo al suyo, nunca le manifestó carta ni constancia alguna ni el declarante lo creyó porque del Marqués de Rayas, tenía el declarante datos contrarios, mediante lo que había oído al Padre Arizmendi de la Orden de San Diego, acerca de su modo de pensar y al Fagoaga no lo conoce y solo sabe que hay muchos de esta familia.

27.- Preguntado: Que pues entró en el partido de la Insurrección, sin concierto de Plan alguno; cual fue a lo menos, el que adoptó para organizarla luego que se vio al frente de ella y poner en orden todas las relaciones y ramos civiles, militares, políticos y de justicia de que se compone todo gobierno bien ordenado.

Dijo: Que no adoptó plan alguno de organización en todo ni en parte, ni se hizo otra cosa más que según se iba entendiendo la insurrección 
DOCUMENTO

dejarlos como estaban, mudando solamente los empleados y lo que el desorden traía consigo, ni tampoco tuvo pensado el que se adoptaría concluida que fuese.

28.- Preguntado: Y cómo se figuraba concluiría felizmente la insurrección y se conciliarían los intereses tan diferentes y encontrados de las diversas castas que componen la masa de la población de este Reino y mayormente habiendo hecho entrever a los indios, según varios papeles que han circulado que ellos son los únicos dueños legítimos de él y si pensaba fomentar la misma insurrección hasta que una sola clase quedara preponderante por la sofocación o aniquilamiento de las demás. Diga si cree de buena fe que la insurrección podía tener un éxito favorable al bien del Reino, en ninguna suposición.

Dijo: Que como entró en la insurrección tan impremeditadamente y después las circunstancias en que se halló no le han dejado tiempo de pensar en Planos; ninguno ha llegado a formar para el caso de verla concluida y bien conoce que formarlo y planificarlo, ofrecería muchas y gravísimas dificultades.

29.- Preguntado: Si es cierto que en todos los pueblos en donde ha entrado él mismo y los demás jefes de la insurrección han dado libertad a todos los reos que había en las cárceles, sentenciados y por senten-

154 ciar, sin excepción de los que lo eran de los más atroces delitos; y si es cierto por qué han tenido esta conducta con unos hombres que deben considerarse como enemigos de la sociedad; y si no contentos con esto han dado grados militares a algunos entre los cuales se cuenta el nombrado Agustín Marroquín, Capitán, a quien el declarante comisionó a seguir su declaración para conducir a la muerte muchos de los asesinados en Guadalajara.

Dijo: Ser cierto lo que inquiere la pregunta y que esto se hizo por atraer la plebe; y confiesa lo mal que se hacía en esto, a que obligaban las circunstancias, como tiene declarado; respecto de otras acciones indisculpables.

30.- Preguntado: Qué fundamentos tuvo y han tenido los partidarios de la insurrección, para calificar al Gobierno Español de tiránico y despótico; que ha tenido esclavizada a la América por trescientos años y a los españoles europeos de tiranos y déspotas, usureros, ambiciosos, enemigos de la felicidad de la América, impíos, traidores, libertinos, vili- 
pendiadores del sacerdocio, asesinos de la Religión, del Rey y de la Patria; que han calificado a los americanos de indignos de toda distinción y honor; que tenían vendido el Reino a una nación extranjera, tan pronto a los franceses; tan pronto a los ingleses; y a sospechosos de que podían venderlo como también para publicar que constaba que la Nación (hablando de la América) iba a perecer irremediablemente y los americanos a ser viles esclavos de sus mortales enemigos (sin expresar cuáles) perdiendo para siempre su religión, su libertad, sus costumbres, y cuanto tiene más sagrado y precioso y que si así no les constase, nunca hubieran desenvainado su espada, contra los europeos según consta de la Proclama del declarante que tiene reconocido ser suya, de las de sus generales y de cuantos papeles anónimos han circulado. Los insurgentes por el Reino, esforzándose a inspirar un odio encarnizado contra todos los europeos y contra el gobierno español.

Dijo: Que aunque se reconoce acreedor a la pena que merezcan los dicterios expresados en la pregunta por haber sido el motor de la Insurrección, no se considera obligado a justificarse de los que no han producido él mismo; y que en cuanto a estos, como son los que se encuentran en la Proclama citada y en El Despertador Americano escritos de su orden, confiesa haber llevado el objeto de inspirar el odio contra el gobierno, no porque tuviese para ello un racional fundamento, si no por que le era necesario para sostener la empresa a que se había decidido, con ligereza a la verdad; pero no sin inclinación nacida de persuadirse que la independencia sería ventajosa al Reino, y corroborada con ver este indefenso y expuesto a caer en poder de una potencia extranjera, especialmente de los franceses a causa de una expresión que había leído en una Gaceta de México, en que se decía que la América debía seguir la hueste de la España y esta es toda la constancia que en su citada Proclama, dice tener de que la América, iba a perecer irremediablemente con lo demás que sigue de la pregunta.

31.- Preguntado: Diga el número y fecha de dicha Gaceta de México y exprese el sentido claro y terminante en que estaba concebida la expresión que está, pues en ninguna parte del Reino se sabe que se halla hecho notable hasta que el declarante reveló este secreto en el pueblo de Dolores y San Miguel el Grande, y en cualquiera caso qué responsabilidad cabía 
DOCUMENTO

a los europeos esparcidos y aislados en diferentes puntos del Reino por una expresión en que no habían tenido parte, ni acaso la habrán visto o entendídola en otro muy diferente sentido.

Dijo: Que no se acuerda del número y fecha de ella; pero que es posterior a la entrada de los franceses en España; que el declarante ha dado a aquella expresión el sentido que tiene expresado, es decir que haciéndose dueño Bonaparte de la España, que la América debía también seguir la misma suerte, y no sabe qué sentido le habrán dado otros y que en nada considera responsables por dicha expresión a los europeos pues tiene confesado fue injusto cuanto se hizo contra ellos y la causa de haberlo hecho.

32.- Preguntado: Quién hizo al declarante juez competente de la defensa del Reino y mucho menos de las ventajas de su Independencia, para arrojarse con tanta ligereza como tiene confesado a una empresa cuyos trámites, éxito y consecuencias le era imposible prever y dominar y que desde luego tenía que empezar cimentándose sobre la injusticia de imputar al Gobierno y a los europeos las más negras calumnias y de causar daños incalculables, destruyendo los resortes más vigorosos del reino y cometiendo infinitos escándalos y atrocidades constantes de su misma declaración.

156 Dijo: Que el derecho que tiene todo ciudadano cuando cree la Patria en riesgo de perderse y responde.

33.- Preguntado: Por qué ha creído este riesgo con una creencia tal cual ninguno otro la creía a la sazón, y por qué no hizo presente al Gobierno su queja o creencia para que pusiese los medios de evitarlo que era lo único a que le daba derecho su creencia, fuera de que hasta ahora no ha presentado datos suficientes para infundirle semejante creencia.

Dijo: Que creyó el riesgo como tiene dicho y que no dio parte al Gobierno porque creyó que no le haría caso, pues veíalo indefenso del Reino y no lo ponía en estado de defenderlo, y responde.

34.- Preguntado: Por qué de creencia en creencia creyó que el Gobierno no le haría caso, pues es bien común en los hombres, no hacer alto sobre las cosas que tienen a la vista hasta que se les advierte lo conveniente, de cuyo número podía ser la que se trata, y sobre todo por qué no dio este paso prudente que era su deber y de poco costo; así como se 
arrojó a la empresa por el derecho y obligación en que está todo ciudadano cuando ve la patria en riesgo de perderse como sienta en su respuesta a la pregunta treinta y tres.

Dijo: Que no tiene más respuesta que dar, que la dada, y responde.

35.- Como funda su creencia sobre un supuesto notoriamente falso, pues ni el Reino estaba tan indefenso como supone, pues no le ha faltado fuerza para destruir al que declara y a todo su partido, sin embargo de haberse hecho tan numeroso por el cebo de la rapiña y menos le hubiera faltado para destruir cualquiera invasión extranjera que por necesidad respectivamente debía ser de poca consideración si toda esta fuerza civilmente dividida hubiese obrado en justa y legítima unión, ni tampoco se tenía en olvido la mayor defensa en el reino, pues parecía y cabalmente desde entonces o antes del acto de la Independencia, se estaba tratando en la capital de México de fundir y se estaban fundiendo cañones y fusiles y llamados allá todos los artífices y oficiales capaces de trabajar en dicho ingenios, y todo para dicho efecto como el declarante debía haberlos visto en la Gaceta de México, y hasta se había abierto una suscripción general para colectar fondos con este destino como era público y notorio.

Dijo: Que siempre le parecía poca la fuerza que había en el Reino y que debía aumentarse y que aunque se empezó en México a trabajar en hacer armas se había suspendido poco antes de la insurrección, y responde.

36.- Preguntado: Por qué daba tanto valor a su parecer para regular su conducta política, posponiendo los de todos los demás y el del mismo Gobierno, y los conocimientos con que debía suponer el declarante dicho Gobierno en el aumento y baja de la fuerza militar y de las armas, necesarias a la defensa del Reino, lo cual hace manifiesto que realmente el declarante, tenía empeño decidido en llevar adelante el sistema de la Independencia y fuese como fuese.

Dijo: Que ésta es una flaqueza por donde pecan comúnmente los hombres, y esta es en realidad la que lo condujo al empeño de la Independencia intentada por la insurrección, responde.

Preguntado: Diga para evacuar completamente pregunta treinta y dos, quién le hizo juez competente de la conveniencia de la Independencia del Reino y lo demás que sigue hasta su conclusión. 
DOCUMENTO

Dijo: Que él mismo se ha erigido juez de esta conveniencia sin contrabalancear la teoría de los obstáculos que las pasiones y la diferencia de intereses que siempre se encuentran en la ejecución de tales empresas no podían faltar a la suya, en esto también reconoce su imprudencia, pues así que fue a los primeros pasos se vio precisado a los excesos que indica la misma pregunta, y responde.

38.- Preguntado: ¿Señor Don Fernando Séptimo al mismo tiempo que se destruía su real patrimonio y se perseguía a un gran número de sus vasallos, sin otro delito que el de ser europeos o era esta contestación una superchería para alucinar a la plebe y empeñarla a seguir su partido, haciéndola criminal como instrumento de aquellos delitos? Dijo: Que el ánimo del declarante siempre fue el de poner el Reino a disposición del Señor don Fernando Séptimo siempre que saliese de su cautiverio, y los excesos que indica la pregunta, no estaba en la intención del declarante, y responde.

39.- Preguntado: Qué garantías podría dar el declarante a esta restitución, cuando está visto por su confesión, que ni por pocos momentos pudo dirigir su empresa, en ningún género de justicia ni equidad? Dijo: Que ningunas, pero que éstas eran sus intenciones, y responde.

40.- Preguntado: ¿Qué seguridad tenía el declarante de esta restitución cuando está visto por su confesión que ni por pocos momentos pudo dirigir su empresa con ningún género de justicia ni equidad? Dijo: Que ningunas, pero que éstas eran sus intenciones, y responde.

40.- Preguntado: Qué seguridad tenía el declarante de que su proyectada Independencia no acabaría lo mismo que había empezado, esto es por una absoluta anarquía o por un igual despotismo, pues ya tiene declarado que cualquiera plan que se formase, su plantificación ofrecería muchas y gravísimas dificultades. Dijo: Que ninguna tenía, y que ahora ha palpado por la experiencia que seguramente hubiera terminado en estas dos cosas y por lo mismo quisiera que a todos los americanos se les hiciera saber esta su declaración, que es conforme a todo lo que siente en su corazón y a lo mucho que desea la felicidad verdadera de sus paisanos, y responde.

El primer número 40, hasta donde dice, $\mathrm{y}$ responde, no vale por estar duplicado dicho número. 
41.- Preguntado: Según lo que lleva declarado fue grande imprudencia y temeridad esperar ningún bien para la felicidad del reino, de esta Independencia buscada por medio de la insurrección, y lo único prudente, acertado y equitativo, hubiera sido esperarlo de las Cortes Generales y extraordinarias de la Monarquía para las cuales estaban nombrados Diputados de ciencia y probidad por todas las provincias, sin otro objeto que el de ilustrar aquel augusto congreso, sobre los arbitrios de dar al Reino las mejoras posibles. Dijo: Que es muy cierto y que solo por una especia de seguridad pudo el declarante pensar de otro modo, y responde.

42.- Preguntado: Confesada y comprobada la ligereza y temeridad del declarante en cuanto al modo y causas impulsivas que lo empeñaron a la insurrección, diga cómo justifica y concilia con la doctrina del Evangelio y con su estado la insurrección misma, apellidar Independencia y romper la unidad política de la Monarquía, alzarse contra las autoridades constituidas que al tiempo de la insurrección gobernaban y gobiernan pacíficamente los pueblos en donde quiera que no penetró la fuerza colecticia y tumultuaria de los revoltosos, levantar ejércitos, declarar la guerra, solicitar alianzas extranjeras, abrogarse el derecho de vida y muerte, atentar contras las propiedades, dar y quitar empleos, atropellar todas las prerrogativas y regalías de la soberanía y sobre todo causar la ruina del comercio, minería, artes y agricultura; los escándalos de hacer enmudecer los legítimos pastores para que no predicasen la santa doctrina, permitir a los malos vender sus fábulas y sofismas, distinguiéndolos por el mismo hecho, poner las manos en los caudales de las Iglesias y fondos piadosos, ahuyentar a los prelados, desacreditarlos en la opinión de sus secuaces, igualmente que al Santo Tribunal de la Fe, para que no fuesen creídos, abriendo en fin, por otros tantos caminos la puerta a la irreligión, al estrago de las costumbres y a la exaltación de las pasiones.

Dijo: Que nada de lo que contiene la pregunta, se puede conciliar con la doctrina del Evangelio y con su estado y que reconoce y confiesa de buena fe que su empresa fue tan injusta como impolítica y que ella ha acarreado males incalculables a la Religión, a las costumbres y al Estado en general, y muy particularmente a esta América, tales que el gobierno más sabio y vigilante, no podrá repararlos en muchos 
DOCUMENTO

años; y asimismo se conoce responsable a todos estos males como voluntarios, en sí o en su causa, todo lo cual es muy sensible a su corazón, y así desea llegue a noticia de su Ilustrísimo prelado, a quien por tantos títulos está obligado y de cuyas luces siente no haber sabido aprovecharse y muy rendidamente le pide perdón de los sustos e incomodidades que Su Señoría Ilustrísima ha tenido que sufrir por su causa; e igualmente lo pide al Santo Tribunal de la Fe de no haberle obedecido y de las expresiones irrespetuosas con que se ha atrevido a impugnar su edicto.

Asimismo lo pide al Excelentísimo Señor Virrey de estos reinos y demás autoridades constituidas por su inobediencia y a los pueblos por el mal ejemplo que les ha dado; en cuya virtud les ruega se aparten de los caminos de la insurrección que no pueden llevarlos sino a su ruina temporal y eterna, y para que este ruego llegue a noticia y surta los debidos efectos, suplica al Señor Comandante General de estas provincias don Nemesio Salcedo, se lo haga saber del modo que tenga por más conveniente, y responde.

43.- Preguntado: Diga pues y manifieste en descargo de su conciencia y del juramento que tiene hecho cuanto sepa y convenga saber al Gobierno para las futuras seguridades y tranquilidad de los pueblos y que no se le reiteren los males pasados.

Dijo: Que por ahora no se acuerda de ninguna cosa importante al Gobierno, pero promete manifestar cualquiera que se le ocurra, y responde.

En este estado, el Señor Juez comisionado don Angel Avella, teniendo por bastante por ahora la declaración que antecede, mandó cerrarla sin perjuicio de continuarla si fuere necesario y habiéndosele leído al declarante, dijo ser la misma que lleva hecha, y su contenido la verdad, a cargo del juramento que lleva prestado, en que se afirmó y ratificó, y firmó con dicho Señor comisionado y conmigo al presente escribano de que doy fe. Angel Avella - Miguel Hidalgo.

Ante mí. Francisco Salcido.

Chihuahua, 7 de junio de 1811. Al Lic. Don Rafael Bracho. Asesoría. Salcedo. 